\title{
Comparison of Non-Destructive and Destructive Testing on Concrete: A Review
}

\author{
Sakshi Gupta* \\ Department of Civil Engineering, ASET, Amity University Haryana, India
}

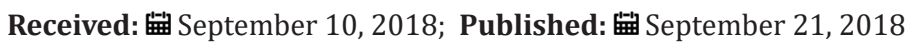

${ }^{*}$ Corresponding author: Sakshi Gupta, Department of Civil Engineering, ASET, Amity University Haryana

\begin{abstract}
Concrete is the oldest and most important construction material in the world. Testing of the concrete specimen plays and important role to know about the strength, durability and condition of the structure. The work will present a detailed comparison between the destructive tests and non-destructive methods. This work focuses on comparing the destructive and non-destructive testing which can determine the potential durability of the concrete. This work helped us to reach a conclusion where we can further find the best testing method system that shall be applicable for various concrete structures as well as in the concrete industry.
\end{abstract}

Keywords: Concrete; Compressive Strength; Destructive Testing; Non-Destructive Testing; Strength

\section{Introduction}

Concrete is the oldest and most commonly used construction material in the world, because of its durability, low cost and high availability Hassan [1]. It provides the most cost effective and efficient means of construction. Testing of concrete ranges from non-destructive where there the concrete specimen is not damaged to destructive testing where the concrete specimen might be slightly or completely damaged. 2 billion tons of concrete was produced in the year 2004 in the world, with India contributing 116.1 million tonnes Bhatacharjee, [2]. In today's world concrete is made using various kinds of cement, coarse/fine aggregates, water, and admixtures if any. Proper infrastructure is one of the biggest drawbacks that halt the growth in India. The 12th five-year plan laid a special focus on the growth of infrastructure in India i.e. roads, highways, railways, communication and ports. One trillion is being invested in this sector during the 12th year plan. The world views India as a capable nation which is expected to show a growth from 1.2-1.5 billion by 2040 surpassing China which is already leading as the most popularly grown nation Rai and Ghavate [3]. A recent global report "Global Construction 2020" estimated India to be the third largest global construction market after USA and China. Today, the enhancement in the design capacity in India has reached a level where it is possible to design concrete with strengths of more than $100 \mathrm{MPa}$ which wasn't possible earlier. China has already used concrete strength up to $80 \mathrm{MPa}$ for high rise building construction within the cement usage set by the code standards Chatterjee [4].

The destructive testing method is suitable and economically beneficial for the concrete specimens that are produced at a large scale. The main aim is to investigate the service life and detect the weakness of design which might not show under normal working conditions. It includes methods where the concrete specimen is broken so as to determine mechanical properties i.e. hardness and strength. This type of testing is very easy to carry out, easier to interpret and yields more information. Some popular destructive test methods are as follows Shankar and Joshi [5]:

I. Tests of mechanical properties using the universal testing machine (UTM):
a) Tensile testing.
b) Bending testing
c) Compressive testing
II. Hardness testing.
a) Brinell test
b) Rockwell test
III. Impact testing
a) Pendulum test
b) Drop weight test

Destructive testing includes mechanical testing (bending, impact tests, tensile), macro/microhardness testing as well as metallographic examination. The various advantages of destructive testing are listed below: 
A. Tests are economical and can be performed at a cheaper rate.

B. Equipment cost for destructive testing is cheap as compared to non-destructive testing.

C. It identifies mechanical properties (fracture strength, elongation, and modulus of elasticity)

D. It helps to reduce failures, accidents, and costs.

E. It helps in verifying the properties of the material Shankar and Joshi [5].

The various disadvantages of destructive testing are:

a. The internal defects of the concrete i.e. bubble, pores etc. can't be determined.

b. The concrete specimens cannot be used again after the testing.

c. It cannot be used to detect early age deformities in concrete Kumavat et al. [6].

Non-destructive testing (NDT) is mainly concerned with the evaluation of flaws in materials which are in the form of cracks and which might lead to loss of strength in a concrete structure (Samson et al. [7]. NDT is a method for the testing of existing concrete structures so as to determine the durability and strength. In the modern construction world, it has become a vital part of the quality control process. NDT also helps in investigating about the crack depth, deterioration and microcracks present in concrete. Large no of parameters like density, strength and surface hardness can be determined by using NDT methods. It is also possible to check the integrity of structure and quality of workmanship by detecting cracks and voids Kumavat et al. [6]. It is applicable on both new as well as existing structures. Various NDT methods used in the field are as follows:

i. Rebound hammer test

ii. Ultrasonic pulse velocity test

iii. Combined ultraviolet and rebound hammer test iv. Core extraction test

v. Ingredient analysis test.

The main aim of NDT is to assess one or more of in situ strength properties i.e. density, durability, and moisture content. NDT is the only way to assess the depth of cracks and to investigate whether any structural damage has occurred. Structural health monitoring by NDT like rebound hammer and UPV becomes very useful for the prediction of the service life of structure (Hannachi and Nacer, 2012). Experimental investigations determine that a good correlation exists between rebound hammer, UPV, and compressive strength. Rebound hammer test can be used alone to determine the compressive strength of concrete. UPV is an ideal NDT method to predict the deterioration of structures and the service life of structures. NDT has a vital role in everyday life and is very important to ensure reliability and safety. The main advantages of non-destructive testing are listed below:

I. The probe test generates variable results and provides the fastest means of checking maturity and quality of concrete.

II. Schmidt hammer test provides a simple, quick and inexpensive method of obtaining the indication of the strength of concrete with an accuracy of 15 to $20 \%$.

III. Pull-out tests give information on development and maturity IV. UPV method is the most ideal tool for determining whether concrete is uniform or not.

V. Radioactive equipment testing is very simple, and the running cost is less, although the initial price might be very high.

The main disadvantages of non-destructive testing are:

A. Interpretation of results is difficult.

B. The manual operation requires experienced and skilled technicians.

C. It is difficult to inspect the concrete specimens that are irregular and full of voids Kumavat et al. [6].

\section{Literature Review}

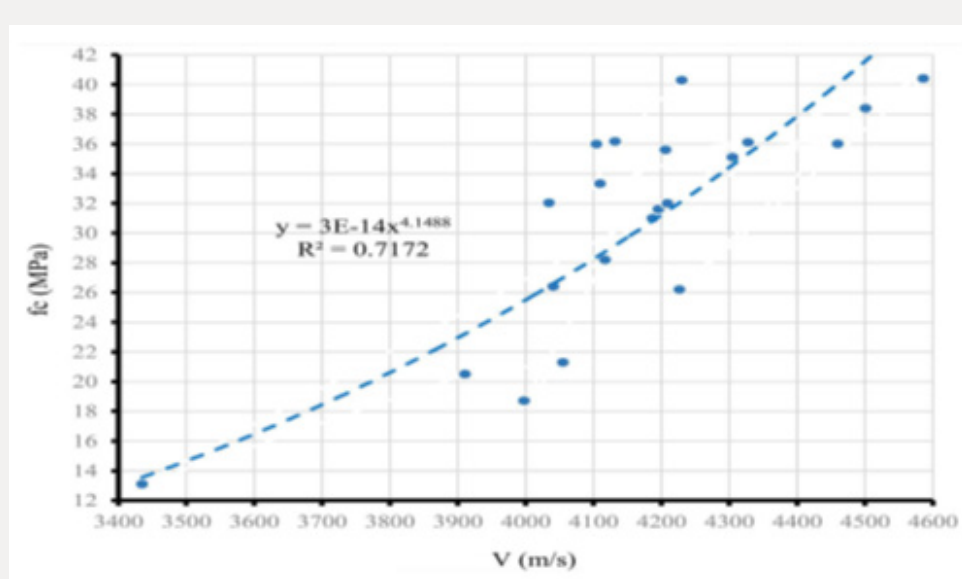

Figure 1: Compressive strength vs velocity of concrete specimens Lopez et al. [8]. 
Kumavat et al. [6] carried out an experimental study on combined methods of NDT in concrete and evaluation of core specimen from existing buildings. Ultra-pulse velocity rebound hammer and core tests were carried out on the specimens according to IS standards and combining the two methods. Regression analysis was carried out and correlation coefficients were given. Charts were plotted between rebound numbers, UPV against the compressive strength of the core specimen. The comparison showed that use of combined methods gives higher efficiency on estimation of concrete compressive strength. The results obtained gave a correlation coefficient of 0.003 and 0.355 for rebound value and UPV value. A higher correlation coefficient of 0.441 was obtained when two methods were combined. Lopez et al. [8] experimentally studied the concrete compressive strength estimation by NDT. The main aim was to produce a correlation between results of surface hardness, UPV and compressive strength of structural concrete in bleachers of a soccer stadium in Parana, Brazil. The concrete structure used in the study was 26 years old and had some severe deformities i.e. segregation, corrosion, and cracks. Mapping reinforcement was performed and UPV test was done according to the IS standards. 26 specimens of concrete were collected and correlation curves between NDT results were plotted. The results showed that stronger the concrete, higher shall be its surface index as well as its wave propagation velocity. Results also showed a good correlation between both surface hardness test and UPV test (Figure 1).

Bhosale and Salunkhe [9] experimentally found the relation between destructive and non-destructive tests on concrete. Different concrete mixes of M20, M25, and M30 were used and a slab of $2000 * 1000 * 200 \mathrm{~mm}$ was casted for each grade and cores were extracted from the slab. Cylinders of size $100 * 200 \mathrm{~mm}$, Cubes of size $150 * 150 * 150 \mathrm{~mm}$ and cubes of $150 * 150 * 150 \mathrm{~mm}$ with an inserted bar of size $16 \mathrm{~mm}$ were cast. Casted cubes after 28 days were tested to obtain compressive strength using CTM. Rebound hammer test was performed and an average of 12 readings was taken. Regression analysis was done, and various correlations were achieved which are given as follows:

1) The relation between the compressive strength of cylinders (f cyl) and cores (F cor)

$$
\text { F cor }=-0.034 \text { f cyl2+ } 2.586 \text { f cyl }-19.25
$$

2) Relation between rebound strength of cylinders (R cyl) and cores (R cor)

R cor $=-0.020$ Rcyl2+2.15 R cyl -16.75

3) Relation between rebound ultra-pulse velocity of cylinders (U cyl) and cores (U cor)

$\mathrm{U}$ cor $=1.373 \mathrm{U}$ cyl2 $+12.18 \mathrm{U}$ cyl -22.95

4) Relation between rebound strength ( $R$ cor) and UPV strength of cores (f cor)

R cor $=-0.050 \mathrm{f}$ cor $2+3.987 \mathrm{f}$ cor -31.16

5) Relation between UPV (U cor) and compressive strength (f cor) of cores

\section{$\mathrm{U}$ cor $=-0.003 \mathrm{f}$ cor $2+0.18 \mathrm{f}$ cor +1.410}

6) Relation between rebound strength and UPV of cores

$\mathrm{U}$ cor $=-0.002 \mathrm{R}$ cor $2+0.166 \mathrm{R}$ cor +1.671

7) Relation between rebound strength and compressive strength of cylinders

R cyl $=-0.037$ f cyl $2+2.712$ f cyl -19.85

8) Relation between UPV and compressive strength of cylinders

$\mathrm{U}$ cyl $=0.0222 \mathrm{f}$ cyl +3.64

9) Relation between rebound strength and UPV

$\mathrm{U}$ cyl= $0.001 \mathrm{R}$ cyl2-0.052 R cyl +4.355

\section{Compressive strength Vs Cube Number}

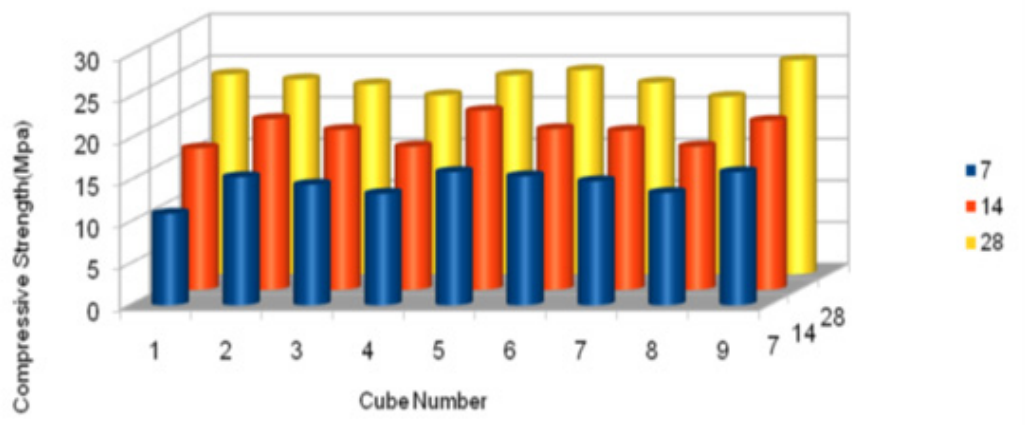

Figure 2: Compressive strength vs. cube no at 7, 14 and 28 days Patil et al. [10].

Patil et al. [10] deduced the comparative study of the effect of curing on strength of concrete using DT and NDT methods. 27 cubes of M25 grade were casted and allowed to be cured for 7,14 and 28 days and rebound hammer test and compressive strength test was performed on 9 cubes of 7, 14 and 28 days respectively. The results showed that the rebound number increased as the compressive strength increased and vice-versa. For 28 days of curing decrease in percentage, strength was less as compared to 7 days percentage 
decrease in strength and average error in measuring compressive strength for 7, 14 and 28 days by rebound hammer and CTM was found out to be $20.01 \%, 1.37 \%$, and $0.99 \%$ respectively. Results also showed that compressive strength or rebound number could be produced if only one of the values was known (Figure 2).

Balwaik [11] experimentally compared the direct, semi-direct and indirect method of testing. A randomly selected school building was taken and a complete analysis of all the structural members was carried out using the direct method of testing. Various defects like air gaps, hollow spaces and voids were identified and all the structural members were grouted at junction points so as to avoid collapsing of members. Results showed that direct UPV method was found to be reliable in detecting of the flaws as compared to indirect and semi-direct methods of testing. Damodar and Gupta (2014) experimentally investigated to develop an ideal curve equation for early prediction of concrete's compressive strength. OPC, PPC and PSC cement were used in the experimental work.18 cubes of the 1st batch of M20, M25, and M30 grade were cast and subjected to normal curing. 3 cubes from every mix were tested for compressive strength at 1 and 3 days respectively and the result of an average of 3 cubes was taken. Results obtained from the experiment showed that OPC gained strength of $80 \%$ in the 1st day of accelerated curing while as PSC and PPC only gained 50\% strength in the 1st day and these results could be used in future for prediction of the early strength of concrete. Results also showed that an ideal curve equation could be obtained and used in computing the compressive strength of concrete (Table 1). The gain in compressive strength is given by: $y=(a b) x$

Table 1: Compressive strength comparison of Mix M20, M25 and M30 in MPa (Damodar and Gupta, 2014).

\begin{tabular}{|c|c|c|c|c|}
\hline Mix Grade & $\mathbf{1}$ day & $\mathbf{3}$ days & $\mathbf{7}$ days & $\mathbf{2 8}$ days \\
\hline Mn20-OPC & 4.00 & 9.39 & 19.55 & 23.48 \\
\hline Ma20-0PC & 19.25 & 18.17 & 16.55 & 23.48 \\
\hline Ma20-PPC & 12.74 & 10.22 & 19.92 & 24.44 \\
\hline Ma20-PSC & 11.7 & 11.48 & 24.07 & 28.74 \\
\hline Mn25-OPC & 5.17 & 11.78 & 24.07 & 28.74 \\
\hline Mn25-OPC & 22.96 & 22.37 & 17.33 & 23.70 \\
\hline Ma25-PPC & 13.48 & 11.18 & 19.25 & 25.33 \\
\hline Ma25-PSC & 12.66 & 12.10 & 24.74 & 30.74 \\
\hline Mn30-OPC & 5.53 & 12.93 & 24.74 & 30.74 \\
\hline Mn30-OPC & 24.88 & 23.77 & 22.96 & 31.70 \\
\hline Ma30-PPC & 17.18 & 14.44 & 22.41 & 28.29 \\
\hline Ma30-PSC & $14.29 \quad$ Where n-normal curing, a-accelerated curing \\
\hline
\end{tabular}

Where, y represents compressive strength, a represents factor comprising parameters of various design mixes, $b$ represents the coefficient of no of days the system has been subjected to curing and $\mathrm{x}$ represents no of days the cubes which are subjected to curing.

Savaliya et al. [12] studied the effect of age on mortar and concrete specimens through an experimental program. 6 concrete and mortar beams of size $(150 \times 150 \times 700 \mathrm{~mm})$ and 6 concrete and mortar cubes of size $(150 \times 150 \times 150 \mathrm{~mm})$ were cast and subjected to direct, indirect and semi-direct UPV testing at 7, 28 and 56 days respectively. Results showed various relations between velocities of UPV, the age of mortar and concrete. The relation between velocity and age of concrete, where y represents the ultra-pulse velocity and $\mathrm{x}$ represents the age of concrete

$$
\mathrm{y}=0.0244 \ln (\mathrm{x})+4.6277
$$

The relation between velocity and age of mortar, where y represents the ultra-pulse velocity and $\mathrm{x}$ represents the age of mortar.

$$
\mathrm{y}=0.1132 \ln (\mathrm{x})+3.2871
$$

The results also showed that velocities measured by keeping the transducers on the bottom and top surfaces in semi-direct UPV testing gave different results. The relation between age of concrete and velocity of transducers on the top surface, where y represents the velocity and $x$ represents the age of concrete.

$$
\mathrm{y}=0.1051 \ln (\mathrm{x})+4.7836
$$

The relation between age of concrete and velocity of transducers on the bottom surface, where y represents the velocity and $x$ represents the age of concrete

$$
\mathrm{y}=0.0469 \ln (\mathrm{x})+5.0426
$$

Nacer and Hannachi [13] investigated the application of the combined method of UPV and RH tests for calculation of compressive strength. UPV and RH tests were measured with mechanical tests done on cylindrical specimens. The tests were used to arbitrate quality of concrete using regression analysis modes. Equations were obtained by statistical analysis to analyses concrete's compressive strength on site. Correlation charts were plotted, and regression equations were listed (Table 2). The results showed that using more than one NDT provided a better correlation and lead to predictable evaluation of concrete's strength. The results also showed that combined methods appeared more appropriate on conditions of on-site measurements as they were very fast, convenient and cost- 
efficient. Shang et al. [14] found the strength of concrete using NDT methods using experimental study. All the samples were made from locally available materials and were confirmed to Chinese standard (GB 175-2007). Five sets of M20, M25. M30, M40, and M50 mixes were prepared and each containing 21 concrete cube specimens of the size $(150 \times 150 \times 150 \mathrm{~mm})$. Rebound hammer test was performed on the specimens and 16 readings were taken for each specimen. Regression analysis was done, and curves were drawn for the rebound hammer method. Results showed that the rebound hammer was found reliable in predicting the early strength of concrete. It was concluded that regression models for the assessment of strength could be used for prediction of concrete strength (Table 3). Shariati et al. [15] assessed the strength of RC structures through UPV and rebound hammer tests and an Table 2: Regression equations for Cylindrical and core Specimens interrelationship between DT and NDT tests was established. Main members of an existing building including a column, beam, and slab were tested by NDT. Regression analysis was done, and calibration curves were drawn. Correlation between predicted and actual compressive strength of concrete was interpreted by plotting average rebound no/ultrasonic pulse velocity against the compressive strength of each member. Results obtained from the experimental study showed that the regression model achieved from the combination of two NDT methods was more precise as compared to the individual methods. Results also showed that the rebound number method was more effective in forecasting the compressive strength of concrete than the UPV test method. The best-fit curve that represents the relationship for UPV results has the following equation:

(Hannachi and Nacer, 2012).

\begin{tabular}{|c|c|c|}
\hline \multicolumn{3}{|c|}{ Cylindrical Specimens } \\
\hline Rebound hammer method & $\mathrm{fc}=-0.7708 \mathrm{~N}+54.6389$ & $\mathrm{R} 2=0.3983$ \\
\hline Ultra-pulse velocity method & $\mathrm{fc}=-0.0162 \mathrm{~V}+97.54095$ & $\mathrm{R} 2=0.5213$ \\
\hline Combined method & $\mathrm{fc}=0.5752 \mathrm{~V}-0.0261 \mathrm{~N}+121.2976$ & \\
\hline & Core Specimens & $\mathrm{R} 2=0.0864$ \\
\hline Rebound hammer method & $\mathrm{fc}=0.3218 \mathrm{~N}+5.3290$ & $\mathrm{R} 2=0.0901$ \\
\hline Ultra-pulse velocity method & $\mathrm{fc}=0.0088 \mathrm{~V}-20.2771$ & $\mathrm{R} 2=0.1251$ \\
\hline Combined method & $\mathrm{fc}=0.0993 \mathrm{~V}+14.5356 \mathrm{~N}-0.0037 \mathrm{~V}-371.4$ & \\
\hline
\end{tabular}

Table 3: Rebound Curve for Concrete measurement and error (Shang et al., 2012).

\begin{tabular}{|c|c|c|}
\hline Regression Model & Function Expression & Correlative coefficient \\
\hline Exponential function 1 & $\mathrm{f}_{\mathrm{cu}}^{\mathrm{c}}=6.004665 \times \mathrm{xe}(0.47 \times \mathrm{xm} 0.017 \mathrm{xdm})$ & 0.824 \\
\hline Exponential function 2 & $\mathrm{f}_{\mathrm{cu}}^{\mathrm{c}}=278.28 \times \mathrm{xe}(-77.23 / \mathrm{Rm}+0.009 / \mathrm{dm})$ & 0.850 \\
\hline Logarithm function & $\mathrm{f}_{\mathrm{cu}}^{\mathrm{c}}=-235.71+75.30 \times \ln (\mathrm{Rm})-0.53812 \times \quad \ln (\mathrm{dm})$ & 0.868 \\
\hline Power function & $\mathrm{f}_{\mathrm{cu}}^{\mathrm{c}}=0.028 \times \mathrm{Rm} 1.9629 \times \mathrm{dm}-0.0155$ & 0.824 \\
\hline Power exponential function & $\mathrm{f}_{\mathrm{cu}}^{\mathrm{c}}=6.00468 \times 1.0486 \mathrm{Rm} \times \mathrm{e}-0.0177 \mathrm{xdm}$ & 0.852 \\
\hline Complex exponential function & $\mathrm{f}_{\mathrm{cu}}^{\mathrm{c}}=0.032509 \times \mathrm{Rm} 1.941 \times 10-0.00789 \times \mathrm{dm}$ & \\
\hline
\end{tabular}

fc $(V)=15.533 \mathrm{~V}-34.358$

Where $\mathrm{V}$ is the ultrasonic pulse velocity. The best fit curve that represents the relationship for the combined method has the following equation:

$$
f c(V)=-173.04+4.07 V 2+57.96 \mathrm{~V}+1.31 \mathrm{R}
$$

Where $\mathrm{V}$ is the ultrasonic pulse velocity and $\mathrm{R}$ is the rebound number.

Aydin and Saribiyik [16] carried out an experimental investigation to develop a relationship and correlation between rebound hammer test (NDT) and compression test (DT). Cube specimens of size $15^{*} 15^{*} 15 \mathrm{~cm}$ and a no. of core samples from different RC structures were tested. Rebound hammer test and the compressive test was performed on the specimens. The curves were drawn and the best fit correction factors for concrete compressive strength were obtained through processing the correlation among the datasets. The results drawn from the investigation showed that use of rebound hammer test on existing buildings was not found suitable for evaluation of strength in old structures of concrete. Results also revealed that rebound hammer tests could be used alone as a reliable means to estimate the strength of concrete specimens if the needed calibrations were done (Table 4).

Table 4: Regression outputs for 28 and 90 days concrete specimens (Aydin and Saribiyik, 2010).

\begin{tabular}{|l|c|c|}
\hline 28 days concrete specimens & $\mathrm{y}=11.61 \mathrm{~A}-52.033$ & $\mathrm{R} 2=0.856$ \\
\hline 90 days concrete specimens & $\mathrm{y}=16.674 \mathrm{~A}-238.31$ & $\mathrm{R} 2=0.9449$ \\
\hline
\end{tabular}

Turgut and Kucuk [17] carried out an experimental study to compare direct, indirect and semi-direct UPV testing on 30 concrete blocks of size $(30 \times 30 \times 25 \mathrm{~cm})$ at 28 days. 6 locations were taken in each measurement for each concrete block with path lengths of 250, 150, and 195 for direct, indirect, and semi-direct testing respectively. Results showed that average direct UPV was $9 \%$ higher 
than indirect and semi-direct UPV in concrete blocks. Results also showed that direction of casting in concrete affected UPV. It was found out that UPV was less in concrete casting direction than in horizontal direction. The regression analysis was carried out and best fit lines representing the relationships have been summarized in Table 5.

Table 5: Correlations between UPV measurements (Turgut and Kucuk, 2006).

\begin{tabular}{|c|c|c|}
\hline Regression equation (m/s) & $\mathbf{R}^{2}$ & Standard Deviation (s) \\
\hline $\mathrm{V}_{\mathrm{d}}=0.7254 \mathrm{Vc}+1536.4$ & 0.97 & 57 \\
\hline $\mathrm{V}_{\mathrm{d}}=0.687 \mathrm{Vh}+1561.3$ & 0.96 & 62 \\
\hline $\mathrm{V}_{\mathrm{d}}=0.8274 \mathrm{Vs}+931.14$ & 0.93 & 85 \\
\hline \multicolumn{2}{|c|}{ Where $\mathrm{V}_{\mathrm{d}}$ is direct $\mathrm{UPV}, \mathrm{V}_{\mathrm{c}}$ is UPV in concrete casting direction, $\mathrm{V}_{\mathrm{h}}$ is indirect UPV in the horizontal direction and Vs is semi-direct UPV respectively. } \\
\hline
\end{tabular}

\section{Conclusion}

It has been seen from the literatures reviewed that both the destructive and non-destructive tests help in assessing the strength of concrete. At times where the destructive tests on concrete cannot be employed, one prefers to utilize the non-destructive tests. NDT has a vital role in everyday life and is very important to ensure reliability and safety. A number of advantages were discussed for the various tests that are a part of NDT. The researchers at various instances found that the combination of the NDT tests proves to be more accurate and beneficial than one of the tests alone. The results drawn from the investigations also showed that use of rebound hammer test on existing buildings was not found suitable for evaluation of strength in old structures of concrete and rebound test was useful in finding the early strength of concrete. Results revealed that It was concluded by various researchers that regression models for the assessment of strength could be used for prediction of concrete strength. Thus, it is concluded that using more than one NDT provides a better correlation and lead to predictable evaluation of concrete's strength. The results also revealed that combined methods appeared more appropriate on conditions of on-site measurements as they were very fast, convenient and cost-efficient.

\section{References}

1. Hassan Y (2015) Introduction to Concrete Technology. Research Gate 1(6): 21-29.

2. Bhatacharjee B (2010) Sustainability of Concrete Construction in Indian context. Indian Concrete Journal 2(1): 45-50.

3. Rai S, Ghavate P (2013) Current Infrastructure Scenario and Rise in Construction and Allied Industries in India. International Journal of Science, Engineering and Technology Research 2(8): 1-9.

4. Chatterjee P (2015) Our Changing World: Let's Be Ready, Royal Institution of Chartered Surveyors. Volume 1.

5. Shankar S, Joshi H (2010) Comparison of Concrete Properties determined by Destructive and Non-destructive Tests. Journal of The Institute of Engineering 10(1): 130-134.
6. Kumavat R, Patel V, Tapkire G, Patil R (2017) Utilization of Combined NDT in the Concrete Strength Evaluation of Concrete Specimen from existing building. International Journal of Innovative Research In Science Engineering and Technology 6(1): 556-562.

7. Samson D, Omoniyi, Moses T (2014) Correlation between Nondestructive Testing and Destructive Testing of Concrete. International Journal of Engineering Science Invention 3(9): 12-17.

8. Lopez Y, Vannali L, Jose V (2016) Concrete Compressive Strength Estimation by Means of Non-destructive Testing: A Case Study. Open Journal of Civil Engineering 6(4): 503-515.

9. Bhosale N, Salunkhe P (2016) To Establish Relation between Destructive and Non-Destructive Tests on Concrete. International Journal of Engineering Research and General Science 4(2): 634-644.

10. Patil H, Khairnar D, Thube R (2015) Comparative Study of Effect of Curing on Compressive Strength of Concrete by using NDT and DT. International Journal of Science and Advanced Research in Technology 1(6): 1-5.

11. Balwaik S (2015) Efficiency of various ultra-pulse velocity tests in life of concrete structure. International Organization of Scientific Research 12(4): 1-6.

12. Savaliya D, Thaker K, Dave V (2014) Study of Age of Concrete by Various Ultra-pulse Velocity Test Methods on Concrete. International Journal of Civil Engineering and Technology 5(3): 233-337.

13. Nacer M, Hannachi S (2012) Application of the Combined Method for evaluating the Compressive Strength of Concrete in site. Open Journal of Civil Engineering 2(1): 16-21.

14. Shang H, Ting Y, Yang L (2012) Experimental Study on the Compressive Strength of Big Mobility Concrete with Non-destructive Testing Method. Advances in Material Science and Engineering 2(1): 225-231.

15. Shariati M, Hafizah N, Mehdi H, Shafigh P, Sinaei H (2011) Assessing the strength of reinforced concrete structures through UPV and Schmidt Rebound Hammer tests. Scientific Research and Essays 6(5): 213-220.

16. Aydin F, Saribiyik M (2010) Correlation between Schmidt Hammer and destructive Compressive testing for Concretes in existing buildings. Scientific Research and Essays 5(1): 1644-1648.

17. Turgut P, Kucuk D (2006) Comparative Relationships of Direct, Indirect and Semi-direct Ultra-pulse Velocity Measurements in Concrete 42(3): 745-751. 
(C) C) This work is licensed under Creative

To Submit Your Article Click Here: Submit Article

DOI: 10.32474/TCEIA.2018.03.000154

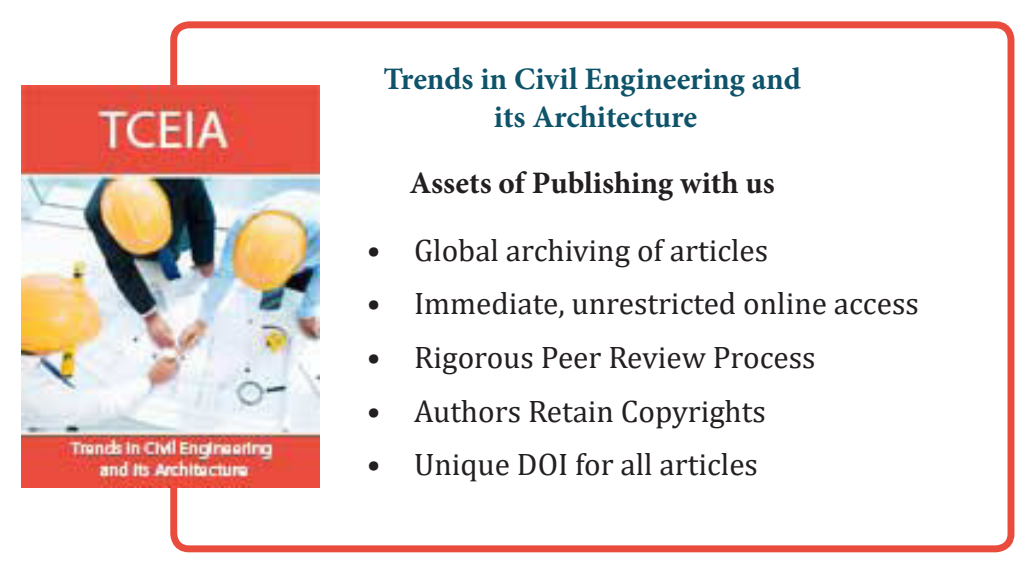

